\title{
Nelson Nadotti e a Invenção do Gaúcho Urbano
}

\author{
Carlos Gerbase ${ }^{1}$ \\ PUC-RS \\ gerbase@terra.com.br
}

\begin{abstract}
Resumo: O imaginário do gaúcho nos outros Estados do Brasil era o de um homem andando em seu cavalo, nos pampas, de bombacha e com um chimarrão. Neste ensaio, aborda-se a importância do cinema de Nelson Nadotti para a desconstrução deste mito e o surgimento da possibilidade de enxergar-se o gaúcho como um sujeito urbano, que é obtida principalmente através da representação da consciência de seus personagens.
\end{abstract}

Palavras-Chaves: Cinema, Nadotti, representação do gaúcho urbano

O cineasta gaúcho Nelson Nadotti, nascido em 1959, em Canoas município altamente industrializado, com uma população de mais de $300 \mathrm{mil}$ habitantes, bem ao lado de Porto Alegre - é figura fundamental do cinema gaúcho contemporâneo, por três motivos: é um dos pioneiros no uso artístico da bitola super-8 no Rio Grande do Sul, lá por 1975; teve a capacidade de agregar outros cineastas iniciantes aos seus projetos, criando núcleos paralelos de realização e fortalecendo o cenário da produção local; e deu um valor social e cultural aos filmes de sua "turma", que entravam em cartaz em salas alternativas, ganhavam críticas nos jornais e conquistavam públicos numerosos para uma bitola habitualmente relegada ao "underground" ou à sala de jantar do realizador.

O objetivo principal deste ensaio, contudo, é mostrar uma razão ainda mais relevante para colocar Nadotti num plano superior na trajetória histórica do cinema do Rio Grande do Sul: este canoense, atrás de seus óculos e de sua falsa timidez, fundou um novo imaginário para o gaúcho, ao representar, pela primeira vez, em meados da década de 70, em seus filmes super-8, a

\footnotetext{
${ }^{1}$ Cineasta e professor na Faculdade de Comunicação Social da PUCRS
} 
consciência de personagens urbanos, contemporâneos, próximos da realidade do cineasta, e distantes, muito distantes, dos gaúchos que habitavam corações e mentes do resto do Brasil. Morando no Rio de Janeiro desde 1984, Nadotti continua a prestar bons serviços para o audiovisual brasileiro, no cinema e na TV, mas este seu pioneirismo, que não pode ser esquecido, é, em nossa opinião, o mais importante legado que um cineasta gaúcho já deixou para a cultura cinematográfica do Rio Grande do Sul.

\section{O Gaúcho Cinematográfico da Era Pré-Nadotti}

Muitos trabalhos já foram escritos sobre a imagem que os brasileiros acima do Mampituba - rio que separa o Rio Grande do Sul de Santa Catarina, via BR-101 - têm dos gaúchos. Neste imaginário, o gaúcho geralmente está de bombacha, sobre um cavalo, com uma cuia de chimarrão na mão. O fato de ser bastante perigoso andar a cavalo e tomar chimarrão ao mesmo tempo, principalmente se a água estiver como deve estar - bem quente - é detalhe insignificante. A construção desse pseudo-gaúcho foi um processo lento, que envolve um pouco da história verdadeira de um estado que já pretendeu ser um país, um pouco da realidade de uma economia baseada na pecuária e na agricultura, e muito de um mito construído por três gaúchos - Barbosa Lessa, Glaucus Saraiva e Paixão Cortes - que, em meados da década de 50, decidiram dar às "tradições" gaúchas uma identidade explícita, consolidando e regrando danças, músicas, vestimentas, atitudes e expressões lingüísticas, na busca de uma unidade que, mesmo artificial, acabou provando ser eficiente, tanto para o mercado interno, quanto como produto de exportação para o resto do Brasil. Como lembra bem Juarez Fonseca:

\footnotetext{
“(...) Paixão bateu pé para que o figurino de prenda fosse o bolo de noiva que conhecemos. Foram para o mesmo balaio, então, um traje usado nas lidas campeiras, o do homem (que nas cidades e nas festas usava as roupas normais da época), e um vestido de festa como o que vemos em museus da nobreza européia" (FONSECA, 2005).
} 
Assim, nossa "prenda gaúcha”, com aquele vestido rodado e cheio de frescuras, virou uma representação das bravas mulheres que habitam os nossos sítios e fazendas, perdidos em nossas belas coxilhas, enquanto uma vestimenta para os homens que estão nas lides campeiras virou uniforme oficial dos peões para todos os lugares e todas as horas.

O cinema feito no Rio Grande do Sul, principalmente no início da década de 70, era constituído por filmes de temática majoritariamente rural, enredos ingênuos e precariedade narrativa. Apesar disso, alcançaram grande sucesso popular, pelo menos dentro das fronteiras do estado. Pereira Dias dirigiu “Janjão não dispara, foge" e "Não aperta, Aparício", ambos cheios de cavalos e chapéus de abas largas. No importante ciclo de longas-metragens de Teixeirinha, quase todos bem sucedidos comercialmente, já é um outro tipo de gaúcho que aparece: mais suburbano que rural, mais estereótipo que mito, mais brega que heróico. Em todo o caso, não era um gaúcho capaz de representar, com alguma verdade, nem a população das cidades de um estado já bastante industrializado, nem o cotidiano duro de pequenos agricultores que começavam a ser atingidos pela devastadora monocultura da soja. Nestes filmes, a bombacha não é traço cultural, nem veste de trabalho: é o traje de fantasia do "gaúcho".

Os filmes rodados no Rio Grande do Sul por “estrangeiros” também tiveram um papel na construção desse imaginário. Ainda que baseados em romances de Érico Veríssimo, que estava preocupado em atacar a mitologia, substituindo-a por um realismo crítico, “O sobrado” (1956), de Walter George Durst e Cassiano Gabus Mendes, "Um certo capitão Rodrigo" (1971), de Anselmo Duarte, todos diretores paulistas, e "Ana Terra" (1972), de Durval Garcia, são bons exemplos do tipo de matéria prima que habita o imaginário dos cineastas brasileiros quando a intenção é representar os gaúchos nos filmes.

Os filmes gaúchos de temática urbana do início da década de 70 - "Um é pouco, dois é bom” (1970), de Odilon Lopez, “Um crime no verão” (1971), de 
Américo Pini, e "Um homem tem que ser morto" (1973), de David Quintans, "Pontal da solidão" (1974), de Alberto Ruschel, e "Domingo de Gre-Nal" (1979), de Pereira Dias - tiveram péssimas carreiras comerciais. Eles não eram "piores", do ponto de vista cinematográfico, que os filiados à estética do ciclo bombacha e chimarrão. Mas, ao não se filiarem ao imaginário dominante do gaúcho, perdiam a identidade, condenavam a si mesmos a um limbo cultural e não apresentavam atrativos para o público. De qualquer maneira, em meados da década de 70 o modelo de produção de longas no estado estava quebrado, pois a estética ingênua e campeira, repetida à exaustão, cansara o público.

É interessante notar que, na chamada "Retomada" pós-1990 do cinema brasileiro, que teve seus reflexos na produção gaúcha, vários filmes feitos no Rio Grande do Sul voltaram a abordar o nosso passado rural. Apesar das propostas bem distintas, e dos resultados estéticos bem distantes, estes filmes reforçaram a maneira como os gaúchos sempre foram vistos no território além-Mampituba: sobre cavalos, envolvidos em guerras, longe das cidades e de qualquer refinamento cultural. Em ensaio escrito em 1998, intitulado "O Relinchante Renascimento do Cinema Gaúcho", abordamos brevemente este cenário. Hoje a situação é diferente.

Para o bem do Rio Grande e felicidade geral desta quase nação, hoje o cinema gaúcho é menos eqüino. Os filmes rurais de época continuam a ser produzidos - e é saudável que assim seja -, mas estão acompanhados por filmes de enredo contemporâneo, urbano, ou simplesmente não-relinchante. O "Cerro do Jarau" (2005), do Beto Souza, independente de qualquer juízo crítico/estético, parece apontar para o uso de nossa mitologia e de nossas tradições num contexto mais arejado, mais inovador, mais iconoclasta. Isso deve permitir que nossos filmes, que carregam consigo a nossa cultura e a nossa identidade (eventualmente o nosso sotaque e os nossos cenários, mas isso depende do roteiro), sejam vistos e consumidos como filmes brasileiros, e não como filmes bairristas e separatistas. Que os cavalos relinchem à vontade, nos filmes e fora deles, contanto que, do Mampituba pra cima, não nos 
confundam com uma versão gaudéria do Roy Rodgers. Cremos que a origem dessa saudável diversidade tem a marca do cinema de Nelson Nadotti, especialmente em sua fase super-8.

\section{A difícil arte de representar a consciência humana}

David Lodge, em seu ensaio "La conciencia y la novela", afirma que o pioneirismo na representação da consciência humana na literatura pertence a três romancistas ingleses dos séculos 17 e 18: Defoe (1660-1731), Richardson (1689-1761) e Fielding (c.1707-1754), que usam a autobiografia ou a confissão fictícia para contar as histórias em que um personagem assume um "eu" narrativo. Já Harold Blomm, em "Hamlet - poema ilimitado", apregoa que Shakespeare, ao escrever sua peça mais importante, construiu o "herói da consciência”.

Mas por que é importante refletir sobre a história da representação escrita ou encenada num palco - da subjetividade dos personagens de um enredo ficcional? A resposta é simples: porque nos ajuda a entender a nós mesmos e ao tempo que nos gerou - a modernidade. Ao colocar a consciência no centro de suas obras, escritores e dramaturgos ajudaram a moldar uma nova noção de "humano". Bloom chega a dar a Shakespeare a honra de ter inventado o humano. Lodge dá a Virginia Woolf, James Joyce e Henry James o privilégio de terem revolucionado a literatura. Este último teria criado um novo modo de escrever, o estilo livre indireto, que hoje é ferramenta fundamental dos trabalhadores da palavra, pois permite a rápida alternância entre a objetividade e a subjetividade, característica do romance moderno.

Resumindo: a literatura, o teatro e, é claro, o cinema, não seriam os mesmos se, em determinados momentos de suas trajetórias históricas, o interior das mentes dos seus personagens não tivesse sido cartografado, explorado e utilizado dramaticamente. A representação do mundo sensível - o que pode ser visto, ouvido, tocado, cheirado e detectado pelo paladar - é parte importante da arte, mas o mundo da mente - em especial a consciência - 
também é matéria-prima fundamental e primária, quando a intenção é criar, mesmo que na ficção, um homem por inteiro.

Esta não é uma tarefa fácil, especialmente para o cinema. A literatura tem longa experiência na elaboração verbal da consciência humana. E poderíamos afirmar, sem medo, que Joyce, em "Ulisses" (1922), obteve uma representação tão magistral que desafia até hoje seus intérpretes, do mesmo modo que um psicanalista "de verdade" é desafiado por seu paciente "de verdade". Ao lermos "Hamlet”, também perceberemos que o teatro é capaz de vencer este desafio.

J.Boorstin, em "O Nariz de Cleópatra", diz que o escritor atua como “consciência do mundo" e aponta os ensaios de Montaigne (1533-1592) como os fundadores de um discurso que desbrava o mundo particular, numa "surpreendente aventura do autoconhecimento" (BOORSTIN, 1996). Montaigne chegava ao mundo, mas partia sempre dele mesmo, de sua própria consciência, que atuava como um microcosmo da natureza humana. Boorstin lembra ainda Descartes (1569-1650) e Pascal (1623-1622), para então chegar a William (e seu irmão Henry) James e a James Joyce, mesmo porto final das reflexões de Lodge.

Quanto ao cinema, que pareceu estar predestinado a capturar o mundo exterior de uma forma tão realista, com tamanha verossimilhança, que alguns negavam-lhe a ação de "representar", base de toda forma artística, este também aprendeu, passada a febre de Bazin e companhia, que só conseguiria firmar-se como arte se passasse a explorar a mente humana, o "interior" dos personagens, fazendo uso de todo seu arsenal sígnico, com o mesmo afinco destinado aos cenários, à exterioridade, ao que olhos e ouvidos têm acesso direto.

A questão do acesso é ponto fundamental nesta análise. Um cineasta, ao apontar a câmara para algum corpo físico que esteja gerando ou refletindo luz, conseguirá sempre, desde que seguidos alguns parâmetros técnicos básicos, ter acesso a uma imagem deste corpo, sobre filme (usando a 
fotossensibilidade dos sais de prata, em processo químico), ou sobre suporte magnético (usando, por exemplo, a fotossensibilidade do selênio, em processo elétrico). Mas a câmara, em si, é incapaz de fotografar, filmar ou gravar a consciência humana, gerando uma representação minimamente aceitável. Nem a câmara, nem qualquer ferramenta já inventada pelo homem. Apesar de numerosos progressos da neurociência, a paisagem e o funcionamento da mente humana ainda é cheio de mistérios. Tomografias computadorizadas, ressonâncias magnéticas e aparelhos semelhantes, mas às vezes tão sofisticados que só seus inventores os compreendem, fazem os cientistas criarem, em suas próprias consciências, modelos da consciência humana. Mas não há máquina que a represente.

Damásio afirma que a máquina mais próxima da representação da consciência humana é o cinema, o que é uma idéia paradoxal, mas muito interessante. Enquanto a literatura tem a riqueza quase infinita dos sentidos conotativos das palavras, o que a faz um instrumento maravilhoso para comunicar idéias, emoções, enfim, estados da consciência humana, de um ser humano para outro, ela é incapaz de denotar imagens e sons sincronizados com o realismo plástico e auditivo de um filme. O que faz do cinema, comparativamente, um instrumento pobre para comunicar idéias pessoais, mas uma máquina poderosa para representar estados de consciência, pois a câmera tem a capacidade de assumir o ponto de vista de um determinado personagem, por um breve estado de tempo, ou até por longos períodos.

Essa representação, contudo, é obtida por um processo semiótico, artificial, discursivo, e não pelo simples ato de apontar a câmera para um corpo físico. Para que o espectador de um filme compreenda que está diante de imagens e sons que representam, de alguma forma, a consciência humana - desde um simples ponto de vista, estritamente visual-sonoro, até uma complexa construção mental, como uma memória distante resgatada naquele momento, ou um exercício de imaginação para o futuro - o cineasta precisa articular a linguagem cinematográfica de modo sofisticado. Ou, em outras 
palavras, o cineasta precisa "mentir", ação precípua de qualquer linguagem. Umberto Eco costuma chamar o cinema de "a mais poderosa máquina de mentir já inventada pela humanidade". O problema é que "mentir" sobre o que a câmara captura explicitamente do mundo exterior é bem mais fácil que "mentir" sobre o que se passa no interior da consciência humana. Na opinião de Eco (que compartilhamos) uma linguagem só é eficiente para comunicar a verdade (ou qualquer outra coisa) se souber mentir.

A literatura gaúcha dos últimos 30 anos fez um grande esforço para representar o gaúcho de uma forma menos mítica e menos mistificada. De Caio Fernando Abreu a Moacyr Scliar, de Luis Fernando Veríssimo a Tabajara Ruas (aí está um autor que, em seus livros, consegue desenvolver uma temática rural num registro crítico), de Marcelo Carneiro da Cunha a Lya Luft, de Daniel Galera a Frank Jorge, dezenas de contos, romances e crônicas colocaram no papel gaúchos urbanos, suburbanos e até interioranos que não compactuam com o modelo CTG (Centro de Tradições Gaúchas). Mas, na verdade, eles não conseguiram competir com as milhares de imagens de gaúchos laçando bois em cartões postais. Contra a grande mentira do gaúcho “centauro dos pampas”, presente em todas as mídias e solidificada pelas imagens fotográficas, cinematográficas e televisivas (tanto locais, quanto as geradas pela Rede Globo), era preciso lançar uma outra grande "mentira" (no sentido da criação de um discurso articulado e artificial) cinematográfica, e aí entra a importância do cinema de Nelson Nadotti.

\section{O canoense que começou a nos tirar da canoa furada}

O cinema de Nelson Nadotti, em sua inicial, que vai de 1975 a 1981, foi assim definido pelo crítico Tuio Becker:

\footnotetext{
"Nadotti, sozinho ou com outros, produziu uma série de filmes em super-8 que em seu conjunto funcionam como uma visão de mundo. Mais especialmente de um mundo pequeno burguês situado ao Sul do Brasil, numa capital provinciana onde uma série de personagens jovens, quase todos com a idade do realizador, expressam diante da câmera suas inquietações diante da vida. Um cinema feito objetivamente, à altura do olho, mas
} 
também em redor do umbigo, daí resultando sua fácil comunicação com a maioria jovem que tem sido o público mais fiel do cineasta”. (BECKER, 1981)

A visão de um mundo pequeno burguês, sublinhada por Becker, pode parecer uma visão comum, e até óbvia, na trajetória do cinema mundial e brasileiro; afinal, o cinema nasceu num momento de afirmação da burguesia e da modernidade. De certo modo, o cinema é produto de máquinas inventadas por burgueses e foi utilizado, quase sempre, para legitimar valores burgueses. No cinema gaúcho, contudo, apontar a câmera para "personagens jovens, quase todos com a idade do realizado", que "expressam diante da câmera suas inquietações diante da vida" foi uma novidade patrocinada por Nadotti.

A história do cinema gaúcho na primeira metade do século 20, que hoje pode ser melhor conhecida graças à pesquisa exaustiva de Glênio Povoas, é uma história dominada pelos cavadores, pelos produtores de cinejornais patrocinados pelo Governo e pelos grandes empresários. Apesar dos eventuais surtos de um cinema mais autoral (Eduardo Abelin em Pelotas, por exemplo), foi um cinema que praticamente não deixou marcas para a construção do imaginário do gaúcho. Na segunda metade, conforme já destacamos, os filmes parecem ter se alinhado, de forma consciente ou não, ao Movimento Tradicionalista Gaúcho, que, a partir de 1955, moldou a figura do gaúcho exportada com tanto sucesso para o resto do Brasil.

Assim, Nadotti e seu grupo de colaboradores foram transgressores de um cânone. Contudo, eles não estava sozinho nessa empreitada. Havia pelo menos outra turma de super-oitistas que também investiam contra o cinema relinchante. O grupo de Sérgio Silva, Tuio Becker, Cláudio Casaccia e Vanderlei Ponzi, entre outros, produzia filmes igualmente desvinculados da estética rural. Sérgio Silva, no final da década de 60, realizou "Sem tradição, sem família, sem propriedade" (1969), em que os valores do tradicionalismo gaúcho eram atacados frontalmente. Mas coube a Nadotti dar um passo além: como Becker detecta, seus filmes "ao redor do umbigo" criaram uma empatia vigorosa com o público, que lotava as sessões em cinemas improvisados 
porque identificava-se com os personagens nas telas e vibrava ao ver suas próprias histórias de vida dramatizadas cinematograficamente. Essa identificação, que não ocorria com os filmes da outra turma (apesar de algumas programações conjuntas, que reuniam filmes dos dois grupos), pode ser explicada pelo grau de intimismo das obras de Nadotti, que, à maneira de Woody Allen, não hesitava em usar um humor cáustico e crítico em relação aos personagens e até a si mesmo (vide a foto de "J.Gomes", em "Sexo e Beethoven" (1980), por exemplo).

O "umbigo" de Nadotti, no entanto, tinha limites amplos e generosos. Em "Rita" (1976, mudo), o universo feminino é explorado. Segundo Nadotti:

\begin{abstract}
"Rita significa uma visão meio primária e traumática sobre a condição da mulher na sociedade. Com a consciência de que sempre pode haver o troco, o revide. (...) Um ponto de partida, querendo dar vez à voz do outro". (NADOTTI, 1981)
\end{abstract}

Em “Nas ruas" (1977), Nadotti faz um exercício sobre paranóia, em que um rapaz tímido é perseguido por figuras estranhas e ameaçadoras. Já o "O fim do filme" (1977) está bem próximo do umbigo, pois "diz respeito ao ato de criar, ao poder, à impotência, à resistência, à desistência - e mais duas ou três coisinhas engraçadas". (NADOTTI, 1981)

É justamente quando se mantém próximo ao umbigo que Nadotti consegue imprimir sua marca pessoal aos filmes e mudar a trajetória do cinema gaúcho, o que ficará evidente no longa "Deu pra ti, anos 70" (1980, codireção com Giba Assis Brasil), mas já é detectável três ou quatro anos antes. "Inventário de sombras" (1977), por exemplo, é a história de um adolescente com uma vida afetiva conturbada, cheia de percalços e de dor. Nadotti lembra que "aqui começaram os papos de que os filmes da gente eram autobiográficos".

É importante perceber a expressão "filmes da gente" (e não "meus filmes”) usada por Nadotti. Em 77, ele não era um realizador solitário, e sim o capitão de um time que incluía outros jovens cineastas, que compartilhavam 
não só um modo de produção, mas também uma mesma temática e traços estéticos muito semelhantes. Em "Vidafilme" (1978) e "Doloroso amor" (1979), mais uma vez o time produziu filmes auto-referentes. Nadotti, sobre "Vidafilme":

\begin{abstract}
"Por que eu fiz um filme desses? As pessoas à minha volta, amigos e colaboradores, estavam numa espécie de clímax de crise de vida, aos vinte anos. Faculdade enchia o saco, as transas amorosas eram amargas, o trabalho não satisfazia. Choros, brigas, inércia - tinha muito daquilo em 1978. Pelo menos assim me pareceu. E assim senti e passei adiante". (NADOTTI, 1981)
\end{abstract}

Sentir o que sente sua geração e "passar adiante", na forma de um filme, é um bom resumo de quase toda a obra de Nadotti desse período. Ao retratarse, e aos seus amigos, o cineasta inaugurava um novo período no cinema gaúcho, que teria seu marco mais evidente em "Deu pra ti, anos 70". Mas falta ainda um dado para compreender a trajetória de Nadotti: o modo como ele invadia a consciência de seus personagens.

\title{
Dentro dos personagens de Nadotti
}

Em “Meu Primo” (1979, co-direção com Hélio Alvarez e Carlos Gerbase), a história é simples, quase ingênua - jovem do interior chega a Porto Alegre para tentar a vida, enfrentando muitas dificuldades - mas a narrativa tem uma característica sofisticada: o jovem que chega é recebido por um primo, que nunca aparece no quadro, pois é representado pela câmera. Apesar do filme ser realizado, na maioria das cenas, com câmera objetiva, é no diálogo entre os dois primos (sempre sob o ponto de vista do "veterano" na cidade grande) que o espectador tem acesso à intimidade do personagem principal e pode perceber o seu processo de aculturação ao novo meio. Essa subjetivação da narrativa já aponta para uma preocupação com a consciência dos personagens, que continuará sendo usada nos filmes seguintes, tanto de Nadotti, quanto de seus companheiros.

"Deu pra ti, anos 70" acompanha a trajetória de dois personagens Marcelo e Ceres - durante uma década. Os acontecimentos da História são 
revisitados na ótica de dois jovens que se encontram e desencontram, concordam e discordam, se amam e se separam. Essa revisão dos acontecimentos (resistência à Ditadura, repressão, choques ideológicos e culturais) ganha uma dimensão humana porque, durante todo o filme, o espectador tem um acesso subjetivo à História.

Mas Nadotti e Assis Brasil (co-diretor e co-roteirista) dão um passo a mais: nos últimos vinte minutos do filme, são apresentados dois sonhos dos personagens principais, que estão dormindo juntos. Esse acesso direto aos inconscientes de Marcelo e Ceres é construído com competência narrativa e é o clímax de "Deu pra ti anos 70", pois diversos signos importantes do enredo - das primeiras relações sentimentais à presença sempre opressiva da Ditadura - reaparecem, mediados pela lógica misteriosa dos sonhos. Na nossa avaliação, este é o primeiro longa-metragem gaúcho que se aventura a um mergulho desse porte na mente dos seus personagens. Mesmo que, eventualmente, outro realizador tenha "filmado um sonho", duvidamos que este sonho alcance o sentido das cenas oníricas de "Deu pra ti". Nadotti e Assis Brasil estavam não apenas construindo um outro imaginário para o gaúcho, urbano e contemporâneo, como também equipavam essa nova imagem com um inconsciente.

Este é, a nosso ver, um dos principais motivos de sucesso de "Deu pra ti" e da sua grande influência sobre uma geração inteira de realizadores gaúchos. Jorge Furtado, por exemplo, afirma que, após assistir a uma sessão de "Deu pra ti” percebeu que era possível fazer cinema no Rio Grande do Sul. O cinema de Furtado, por sua vez, anos depois promovia novos mergulhos na mente de seus personagens, como o grande monólogo interior que abre "O homem que copiava" (2003).

O autor deste ensaio, em "Inverno" (1982), baseado em idéia original de Nelson Nadotti, faz da representação da consciência do personagem principal - acompanhado por 12 dias de inverno em Porto Alegre - o centro de uma narrativa absolutamente intimista. Em vários momentos do filme, imagens e 
sons representam estados da consciência do "herói”. Há lembranças do passado, pequenas premonições e substituições de experiências visuais concretas por imagens geradas pela mente do protagonista.

A forma auto-reflexiva dos primeiros filmes de Nadotti, o ponto de vista de um personagem invisível em "Meu Primo", os sonhos de Ceres e Marcelo em "Deu pra ti, anos 70" e a imaginação - visualizada pelo espectador - do herói de "Inverno" são, a nosso juízo, elementos dramáticos que caracterizam cinematograficamente a figura do gaúcho de um modo muito diferente daquele que vigorou entre 1950 e 1975.

A exemplo de Montaigne, Nadotti partia dele mesmo para chegar ao mundo. Na rápida articulação dos níveis objetivo e subjetivo da linguagem, o cineasta e seus seguidores usaram o "estilo livre indireto", conforme descrito por Lodge. Ao dotar os gaúchos de consciência, Nadotti desafiou uma estética dominante, usando convenções há muito conhecidas pelo cinema do mundo todo, mas que foram pela primeira vez aplicadas com sucesso no Rio Grande do Sul, que tinha sua imagem permanentemente associada a uma figura mítica, rural, eqüestre, descerebrada, o “centauro dos pampas”. Até que ponto esse imaginário já foi modificado, não sabemos dizer, mas acreditamos que, graças ao cinema de Nelson Nadotti, que tanta influência deixou, a figura do gaúcho, hoje, já apresenta maior diversidade, maior riqueza cultural e, o mais importante, uma dose bem mais consistente de humanidade.

\section{Notas e referências bibliográficas:}

BECKER, Tuio. Apresentação. In CINEMA AO SUL. Porto Alegre: Seqüência Produtores Associados, setembro de 1981

BECKER, Tuio. Cinema gaúcho; uma breve história. Porto Alegre:

Movimento, 1986

BLOOM, Harold. Hamlet - poema ilimitado. Rio de Janeiro: Objetiva, 2004 BOORSTIN, Daniel. Nariz de Cleópatra; ensaios sobre o inesperado. Rio de Janeiro: Civilização Brasileira, 2003

FONSECA, Juarez. Os Aiatolás atacam novamente. In Revista Aplauso, n.64. Porto Alegre: Via Design, 2005

LODGE, David. La conciencia y la novela; crítica literaria y creación literaria. Barcelona: Ediciones Península, 2004 
NADOTTI, Nelson. In CINEMA AO SUL. Porto Alegre: Seqüência Produtores Associados, setembro de 1981 